Bond University

Research Repository

\title{
When Does Perceived Hardness Affect Consumers' Judgments: A Conceptual Replication of Krishna and Morrin (2008)
}

Togawa, Taku; Ishii, Hiroaki; Park, Jaewoo; Roy, Rajat

Published in:

Journal of Marketing Behavior

DOI:

10.1561/107.00000051

Licence:

Other

Link to output in Bond University research repository.

Recommended citation(APA):

Togawa, T., Ishii, H., Park, J., \& Roy, R. (2018). When Does Perceived Hardness Affect Consumers' Judgments: A Conceptual Replication of Krishna and Morrin (2008). Journal of Marketing Behavior, 3(3), 241-249. https://doi.org/10.1561/107.00000051

\section{General rights}

Copyright and moral rights for the publications made accessible in the public portal are retained by the authors and/or other copyright owners and it is a condition of accessing publications that users recognise and abide by the legal requirements associated with these rights.

For more information, or if you believe that this document breaches copyright, please contact the Bond University research repository coordinator 


\title{
When Does Perceived Hardness Affect Consumers' Judgments: A Conceptual Replication of Krishna and Morrin (2008)
}

\begin{abstract}
Drawing on the construal level theory, we replicated and extended Krishna and Morrin's (2008) finding that consumers evaluate water quality to be higher when they drink from a hard cup. The results of our two experiments showed that when they touched a hard object, consumers tended to judge a product as of higher quality when they imagined a near future goal. Conversely, the hardness had no association in the distant future condition.
\end{abstract}

\section{Introduction}

Recently, some consumer research has focused on the effects of nondiagnostic haptic cues_-namely, cues that are unrelated or irrelevant to a judgment goal (e.g., Lin, 2013; MeyersLevy, Zhu, \& Jiang, 2010; see Krishna, 2012 for an integrative review). In a pioneering work, Krishna and Morrin (2008) focused on the effect of perceived hardness as an irrelevant haptic cue on consumers' product quality judgments. In the experiments, they asked participants to evaluate the quality of water drunk from either a firm or flimsy cup. Broadly, the findings show that consumers' perception of quality of water was influenced by haptic inputs like firmness of the cup. This effect was moderated by autotelic need for touch (ANFT), which is a general liking for the haptic perception of products independent of any immediate purchase goal (Peck \& Childers, 2003). Specifically, consumers with low ANFT are more likely to judge water as being of higher quality when they touch a firm (vs. a flimsy) cup. 
This study aims to replicate and extend Krishna and Morrin's (2008) study in several ways. First, drawing on the construal level theory, we focused on temporal distance to the goal as a moderator instead of ANFT. Second, to manipulate perceived hardness, we used plastic folders (Experiment 1) and the hardness of paper to print advertisements (Experiment 2) as stimuli, instead of plastic cups. Third, we used different product categories (bathroom scale, electronic dictionary) as our target, whereas the original study participants evaluated water quality. We believe that replication using different stimuli, target product, and a Japanese sample would improve the external validity of the original study's findings. Most importantly, focusing on the moderating role of temporal distance may aid consumer researchers' understanding of when haptics such as hardness influence consumers’ product quality judgments.

\section{Haptics and Construal Level}

Construal level theory posits that when people feel temporally distant from an object, they have a high-level (abstract) construal of that object; thus, they focus on its key, goalrelevant, and abstract elements. By contrast, when the object is temporally near, they focus more on secondary, goal-irrelevant, and concrete attributes of the object (Trope \& Liberman, 2003). This theory could potentially explain various phenomena regarding inconsistency of consumer behavior (Lynch \& Zauberman, 2007).

Maglio and Trope (2012) demonstrated that the effects of embodied experience (e.g., haptics and bodily state) on peoples' judgments can be moderated by their construal level. Specifically, people's judgments tend to be affected by embodied experience only when they imagine near future events (i.e., low-level construal). Based on Maglio and Trope's (2012) findings, we propose that the effect of perceived hardness on consumers' judgments is moderated 
by temporal distance. Specifically, this effect will be observed when consumers imagine a near (not distant) future event.

\section{Experiment 1}

In this experiment, we investigated whether hardness as a nondiagnostic haptic input affects consumers' product quality judgment, and whether this was moderated by temporal distance to their consumption goal.

\subsection{Method}

In exchange for course credit, 193 Japanese university undergraduates $(11.9 \%$ female; average age $=19.99$ ) participated in this study.

We manipulated nondiagnostic haptic inputs by varying the hardness of plastic folders (i.e., hard/soft) enclosing a print advertisement (Fig. 1). The hard and soft plastic folders were almost equal in size (approximately $220 \mathrm{~mm} \times 310 \mathrm{~mm}$ ) and appearance (transparent), and they were made by the same stationary manufacturer (KOKUYO Co., Ltd.). In a pretest, 59 nonparticipants were asked to hold either a hard or soft plastic folder and evaluate their perceived hardness, thickness, and heaviness on a 7 -point scale $(1=$ disagree, $7=$ agree $)$. The results showed that the hard plastic folders were perceived as harder than were the soft plastic folders $\left(M_{\text {hard }}=5.33\right.$ vs. $\left.M_{\text {soft }}=2.66 ; t(57)=7.430, p<.001, d=1.92\right)$. In contrast, the other attributes did not significantly differ between the two types of folder (all $p s>.300$ ). Therefore, the folders appeared to differ only in terms of their perceived hardness. We chose a bathroom scale as the target of the advertisement because of its relevance to the participants.

In the main experiment, we used a 2 (haptic input: hard, soft) $\times 2$ (temporal distance: distant, near) full factorial, between-subjects design. The experiment took place in a university classroom. We gave the participants an advertisement for a bathroom scale enclosed in either a 
hard or soft plastic folder. To manipulate participants' temporal distance (see Maglio \& Trope, 2012, Study 2), we asked them to read the product's information that included a statement such as: "this product would be launched [three months from the date of reading the information/tomorrow]." After reading the advertisement, the participants answered four product quality assessment items scored on a 7-point scale ("This product should be good quality," "This product should be reliable," "The workmanship of the product should be high," and "This product should accurately measure body weight," $\alpha=.816$ ). As a manipulations check, we also asked participants to evaluate the plastic folders in terms of perceived hardness, thickness, and heaviness, using the same items that were used in the pretest.

\section{---INSERT FIG. 1 HERE---}

\subsection{Results}

Three participants failed to complete the survey; thus, they were excluded from the following analyses. The remaining sample comprised 190 participants. Consistent with the pretest, the hard plastic folders were evaluated as harder than were the soft plastic folders $\left(M_{\text {hard }}\right.$ $=4.92$ vs. $\left.M_{\text {soft }}=3.52 ; t(188)=5.769, p<.001, d=0.84\right)$. Meanwhile, the plastic folders' perceived thickness and hardness did not differ (all $p \mathrm{~s}>.663$ ).

Next, we conducted a two-way analysis of variance (ANOVA) with haptic input and temporal distance as independent variables, and perceived quality as the dependent variable. The main effect of temporal distance was not significant $\left(M_{\text {distant }}=5.02, S D_{\text {distant }}=1.005\right.$ vs. $M_{\text {near }}=$ $\left.5.01, S D_{\text {near }}=1.027 ; F(1,186)=.036, p=.850\right)$. On the other hand, the main effect of haptic 
input was significant $\left(M_{\text {hard }}=5.15, S D_{\text {hard }}=.901\right.$ vs. $M_{\text {soft }}=4.87, S D_{\text {soft }}=1.106 ; F(1,186)=$ $3.987, p=.049)$.

Furthermore, there was a significant interaction between haptic input and temporal distance $\left(F(1,186)=4.077, p=.045, \eta^{2}=.021\right)$. As expected, for the near future condition, participants who held the hard plastic folder rated the bathroom scale as being of higher quality than did those who held the soft plastic folder $\left(M_{\text {hard }}=5.29\right.$ vs. $M_{\text {soft }}=4.70 ; F(1,186)=7.761, p$ $=.006)$. For the distant future condition, there was no difference in perceived quality $\left(M_{\mathrm{hard}}=\right.$ 5.02 vs. $\left.M_{\text {soft }}=5.03 ; F(1,186)=.001, p=.980\right)$. Cell means are shown in Table 1.

---INSERT TABLE 1 HERE---

\section{Experiment 2}

In this experiment, we focused on willingness-to-pay (WTP) as a dependent variable. We expected that consumers would tend to indicate higher WTP toward the product when they judged it to be of higher quality (Krishna \& Morrin, 2008). Moreover, in this experiment, the perception of hardness was manipulated in a different way (hardness of paper).

\subsection{Method}

In exchange for course credit, 213 Japanese university undergraduates $(31.9 \%$ female; average age $=21.06)$ participated in this experiment.

We manipulated nondiagnostic haptic inputs by varying the hardness of a print advertisement (i.e., hard/soft). The hard and soft papers were almost equal in size (approximately 
$210 \mathrm{~mm} \times 297 \mathrm{~mm}$ ) and appearance (white). We chose an electronic dictionary as a target product based on its relevance to the participants (undergraduate students).

In the pretest $(n=37)$, we distributed one of two types of paper to the participants and asked them to rate their paper on 7-point scales. The hard paper was evaluated to be significantly harder than the soft paper $\left(M_{\text {hard }}=5.47\right.$ vs. $\left.M_{\text {soft }}=4.33 ; t(35)=-2.373, p=.023, d=.78\right)$. Other differences, such as perceived thickness and texture, were not significant $(p s>.20)$.

In the main experiment, 213 undergraduate business students participated in exchange for course credit. The design was a 2 (haptic quality: hard, soft) $\times 2$ (temporal distance: high, low) full factorial, between-subjects design. We handed participants an advertisement for an electronic dictionary printed on either the hard or soft paper. Temporal distance was manipulated in the same manner as in Experiment 1-that is, the product would be launched either after three months or the next day. After reading the advertisement, participants provided WTP assessments in Japanese yen ${ }^{1}$.

\subsection{Results}

We conducted a two-way ANOVA, with WTP as the dependent variable. The main effect of hardness was significant $(F(1,209)=6.538, p=.011)$. More importantly, the interaction between haptic input and temporal distance was significant at the $10 \%$ level $(F(1,209)$ $\left.=2.778, p=.097, \eta_{p}^{2}=.013\right)$. Consistent with our propositions, for the near future condition, advertisements printed on hard paper resulted in a higher WTP than those printed on soft paper $\left(M_{\text {hard }}=17,529.41\right.$ vs. $\left.M_{\text {soft }}=12,543.02 ; F(1,209)=8.714, p=.004\right)$. For the distant future 
condition, there was no difference between hardness conditions $\left(M_{\text {hard }}=15,219.64\right.$ vs. $M_{\text {soft }}=$ $14,168.52 ; F(1,209)=.406, p=.525)$. Cell means are shown in Table 2

---INSERT TABLE 2 HERE---

\section{Discussion}

We extended Krishna and Morrin's (2008) study successfully, based on the construal level theory (Maglio \& Trope, 2012). Table 3 compares Krishna and Morrin's (2008) findings with the present study. We used different product categories (e.g., bathroom scale, electronic dictionary) and different sample (Japanese students) to show that a haptic quality, like perceived hardness, has implications for consumer decisions. Our findings also show that the effect of perceived hardness does not always occur; rather, it depends on consumers' psychological distance.

The results also have several managerial implications. They suggest that marketers can influence consumers' product quality judgments by manipulating the communication medium's physical hardness. For instance, as the date of a new product launch nears, the advertisements and pamphlets could be printed on hard (instead of soft) paper to enhance the consumers' perceptions of the product quality. Based on the main effect of perceived hardness across both studies, it would be beneficial to showcase products that are meant to be tough and resilient in hard packaging.

In the current study, we draw on literature of construal level theory (Maglio \& Trope, 2012) to examine when hardness affects perceived quality. Nonetheless, it is important to note 
that there could be alternative explanations. For instance, participants in the near (vs. distant) future condition might perceive the purchasing goal as an event with high relevancy and be highly involved in construing the goal (Liberman, Sagristano, \& Trope, 2002; Petty, Cacioppo, \& Goldman, 1981). When high-involvement consumers are forming attitudes, they tend to acquire extensive external information (Celsi \& Olson, 1988), and to incorporate this information with their existing knowledge (Greenwald \& Leavitt, 1984), which Krugman (1965) called "bridging experiences". Thus, in the near future condition, participants may have linked hardness of the advertisement with their prior general knowledge about it (e.g., "companies tend to spend a lot of marketing cost and use high-quality hard paper for the advertisement when they sell a flagship, high-end model"). Conversely, in the distant future condition, it is possible that the feeling of hardness was not strongly connected with consumers' existing knowledge and thus had less influence on participants' quality judgments. Future studies are needed to examine these and other possible explanations and to identify the mechanism underlying our findings. Moreover, to expand our findings' external validity, future studies should focus on other haptic

attributes (e.g., heaviness, texture, and temperature), dimensions of psychological distance (e.g., social and spatial), and product/service categories.

---INSERT TABLE 3 HERE---

\section{References}

Celsi, R. L., \& Olson, J. C. (1988). The role of involvement in attention and comprehension processes. Journal of Consumer Research, 15(2), 210-224. 
Greenwald, A. G., \& Leavitt, C. (1984). Audience involvement in advertising: Four levels. Journal of Consumer Research, 11(1), 581-592.

Krishna, A. (2012). An integrative review of sensory marketing: Engaging the senses to affect perception, judgment and behavior. Journal of Consumer Psychology, 22(3), 332-351.

Krishna, A., \& Morrin, M. (2008). Does touch affect taste? The perceptual transfer of product container haptic cues. Journal of Consumer Research, 34(6), 807-818.

Krugman, H. E. (1965). The impact of television advertising: Learning without involvement. Public Opinion Quarterly, 29(3), 349-356.

Liberman, N., Sagristano, M. D., \& Trope, Y. (2002). The effect of temporal distance on level of mental construal. Journal of Experimental Social Psychology, 38(6), 523-534.

Lin, H. M. (2013). Does container weight influence judgments of volume? International Journal of Research in Marketing, 30(3), 308-309.

Lynch, J. G., \& Zauberman, G. (2007). Construing consumer decision making. Journal of Consumer Psychology, 17(2), 107-112.

Maglio, S. J., \& Trope, Y. (2012). Disembodiment: Abstract construal attenuates the influence of contextual bodily state in judgment. Journal of Experimental Psychology: General, 141(2), 211-216.

Meyers-Levy, J., Zhu, R., \& Jiang, L. (2010). Context effects from bodily sensations: Examining bodily sensations induced by flooring and the moderating role of product viewing distance. Journal of Consumer Research, 37(1), 1-14.

Peck, J., \& Childers T. L. (2003). Individual differences in haptic information processing: The “need for touch" scale. Journal of Consumer Research, 30(3), 430-442. 
Petty, R. E., Cacioppo, J. T., \& Goldman, R. (1981). Personal involvement as a determinant of argument-based persuasion. Journal of Personality and Social Psychology, 41(5), 847855.

Trope, Y., \& Liberman, N. (2003). Temporal construal. Psychological Review, 110(3), 403-421. 


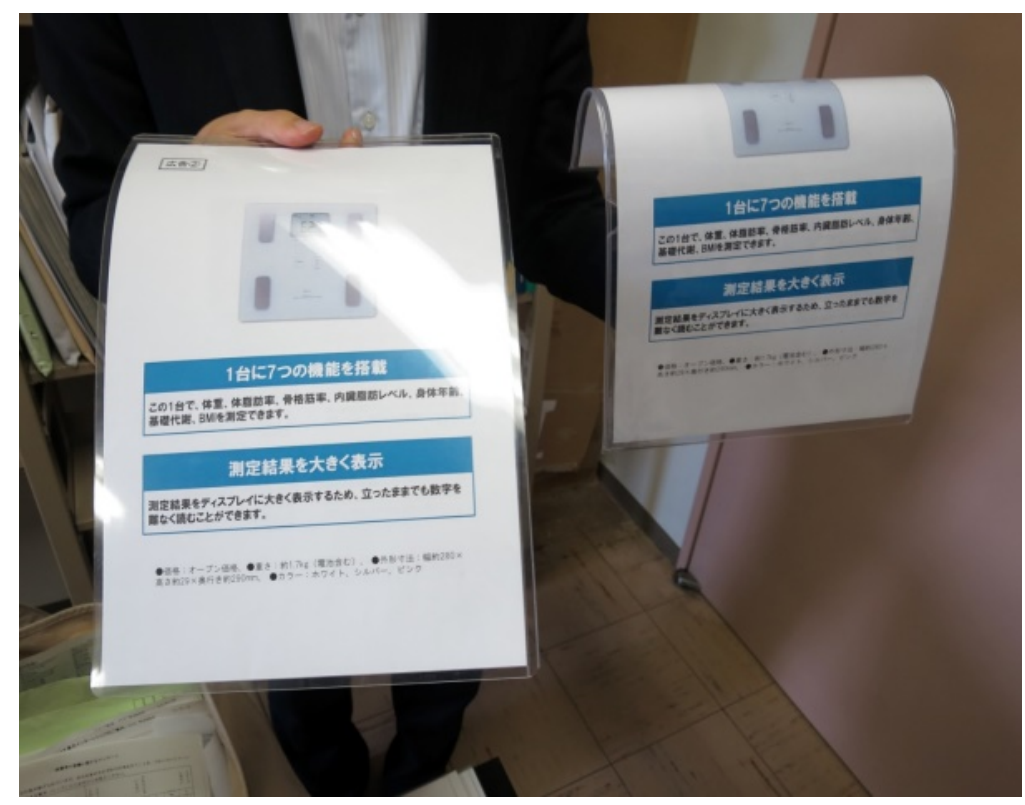

Fig. 1. Hard (on the left) and soft (on the right) plastic folders used in the experiment. 
Table 1. Perceived quality (1 to 7) as a function of hardness and temporal distance

\begin{tabular}{ccc}
\hline & \multicolumn{2}{c}{ Temporal Distance } \\
\cline { 2 - 3 } Near & $5.29(.830)$ & Distant \\
Hard & $n=48$ & $5.02(.956)$ \\
& $4.70(1.140)$ & $n=49$ \\
Soft & $n=44$ & $5.03(1.062)$ \\
& & $n=49$ \\
Difference & $.59^{* *}$ & .01 \\
\hline
\end{tabular}

Note: Figures in parentheses denote standard deviation (SD).

** Indicates that the difference between the two types of folder is significant at $p<.01$. 
Table 2. WTP (yen) as a function of hardness and temporal distance

\begin{tabular}{|c|c|c|}
\hline & \multicolumn{2}{|c|}{ Temporal Distance } \\
\hline & Near & Distant \\
\hline Hard & $\begin{array}{c}17,529.41(9889.293) \\
n=51\end{array}$ & $\begin{array}{c}15,219.64(8964.578) \\
n=55\end{array}$ \\
\hline Soft & $\begin{array}{c}12,543.02(7041.760) \\
n=53\end{array}$ & $\begin{array}{c}14,168.52(8345.145) \\
n=54\end{array}$ \\
\hline Difference & $4,986.39 * *$ & $1,051.12$ \\
\hline
\end{tabular}

Note: Figures in parentheses denote standard deviation (SD).

** Indicates that the difference between the two types of paper is significant at $p<.01$. 
Table 3. Summary of past and current studies

\begin{tabular}{|c|c|c|c|}
\hline & Krishna and Morrin (2008) & Current study (Experiment 1) & Current study (Experiment 2) \\
\hline Participants & Undergraduate non-business students & Undergraduate business students & Undergraduate business students \\
\hline Main IV & Hard/Soft & Hard/Soft & Hard/Soft \\
\hline Main DV & Judgments of product quality & Judgments of product quality & WTP \\
\hline Stimulus & Plastic cups & Advertisement (plastic folders) & Advertisement (sheets of paper) \\
\hline Target products & Water & Bathroom scale & Electronic dictionary \\
\hline Moderators & ANFT & Temporal distance & Temporal distance \\
\hline Key findings & $\begin{array}{l}\text { Consumers with low ANFT were more likely } \\
\text { to evaluate the water more positively when } \\
\text { touching a hard (vs. a soft) cup. }\end{array}$ & \multicolumn{2}{|c|}{$\begin{array}{l}\text { When consumers touched a hard object, they tended to judge a product as of higher quality } \\
\text { (Experiment 1) and indicate higher WTP (Experiment 2). These effects were observed only } \\
\text { among consumers who imagine the near future goal. }\end{array}$} \\
\hline
\end{tabular}

